\title{
Investigating New Paths in the Teaching of Plant Processes in Elementary Schools
}

\author{
Eftychia Nanni ${ }^{1} \&$ Katerina Plakitsi ${ }^{1, *}$ \\ ${ }^{1}$ School of Education, University of Ioannina, Ioannina, Greece \\ *Corresponding author: School of Education, University of Ioannina, University Campus Dourouti, 45110, Ioannina, \\ Greece. Tel: 30-697-289-8463. E-mail: kplakits@cc.uoi.gr
}

Received: July 8, 2013

Accepted: August 5, $2013 \quad$ Online Published: August 11, 2013

doi:10.5430/wje.v3n4p52

URL: http://dx.doi.org/10.5430/wje.v3n4p52

\begin{abstract}
The purpose of this researching study was to develop a teaching proposal and investigate the conceptualizations that children make about the processes of plants (photosynthesis, respiration, transpiration). We undertook an innovative implementation on teaching living things to students of 10 to 11 years old ( 5 th grade). The theoretical framework is the Cultural-Historical Activity Theory that is inherently developed to understand the use of tools in human activity. The researching methodology followed a qualitative design, involving classroom observations and data analysis. The data were classified as students' arguments before the implementation and students' arguments after the implementation. Also, we analyzed how biology education is progressing at schools, under the Cultural-Historical Activity Theory framework. The findings and the results of the analysis were very optimistic and promising. Students participated actively in all educational actions and achieved the goals of teaching the plant processes. Students were able after the teaching to explain in simple terms the concepts of plant processes and also developed positive attitudes and values about living things.
\end{abstract}

Keywords: Cultural-Historical Activity Theory (CHAT); plant processes; primary school students

\section{Introduction}

This study reports part of a wider project inspired by sociocultural theory, which was designed to investigate and improve in-service teachers' training on topics related to living things. The main purpose of the whole project is to design and develop teaching materials, mediating tools, and an innovative teacher education curriculum on the topic of living things.

The project was influenced by the continuing and growing interest of global educational community in the teaching of natural sciences at all levels of education (Next Generation Science Standards, 2013; American Association for the Advancement of Science [AAAS], 1989; Organisation for Economic Co-operation and Development [OECD], 2007; Osborne \& Dillon, 2008). In 2004, the European Commision issued a study entitled Europe Needs More Scientists, thus placing a high priority on science education (European Commission [EC], 2004). On the other hand, nowadays there is so much debate about the Cultural-Historical Activity Theory (CHAT). CHAT is considered a sociocultural theory, and therefore a science education enriched and interpreted by CHAT could be situated in the current sociocultural context (Plakitsi, 2013).

Considering these priorities, we investigate innovative processes and teacher training best practices about living things. Living things is a topic that most science curricula include even from the very early years of schooling as foundational knowledge. However, research has shown that even in late elementary school there is a significant proportion of students who do not have an understanding of the concept of living things that corresponds with biological theory (Venville, 2004).

Based on CHAT analysis, we undertook an innovative implementation on teaching living things to a class of 16 primary students who were 10 to 11 years old ( $5^{\text {th }}$ grade). The study aimed to investigate how primary school students conceptualize plant processes while students are involved with different actions. In our opinion, this study promotes a bottom-up approach, which helps the young children's cognitive development concerning plant processes and also the 
development of school teachers' training programs in teaching science. We studied the way students conceptualize integrated concepts, for example, the characteristics of living and non-living things and the processes of photosynthesis, respiration and transpiration. The unit living/non-living helps students explore the differences between the two, as the world is made up of both living and non-living things, which interact with each other all the time. Also, this unit is a necessary introduction to the unit of plant processes. Overall, our approach to the unit Plants was holistic, since our basic teaching objective is students coming to understand plants as living things with dynamic interactive and interdependent processes.

The research methodology followed a qualitative design, involving classroom observations and data analysis. Students participated actively in all educational actions and achieved the goals of these actions. The findings showed clear differences between students' arguments before and after the implementation. Also, students developed positive attitudes and values about living things (plants) and evolved their communication skills. It is an encouraging finding that most of the students were positive about learning science through active participation and collaborative work in the future. Also, the CHAT analysis showed that the interacting actions in the teaching shared the common goal of the teaching, which was the understanding of plant processes. This case study, even though limited, makes us very optimistic about the implementation of a CHAT analysis in biology education in elementary schools and encourages us to continue our research in this field.

\section{Theoretical Framework}

In 2004, Roth (2004) argued that Yrjö Engeström (1993) called activity theory "the best kept secret of academia", although at the time of Engeström's writing, there was a lively discussion in the former USSR concerning, for example, the work of A. N. Leont'ev (25 citations to his Russian publications in 1992). Nevertheless, Engeström was right in the sense that in the Western and, more specifically, the Anglo-Saxon literature, the activity theory was virtually unknown. The dramatic increase of interest in activity theory in the English-speaking academic circles is, without doubt, in part due to Yrjö Engeström who, through his publications and presentations in a variety of disciplines, spread the word so that activity theory no longer is the secret that it was in 1993.

The contemporary interest in CHAT gave us the impetus to do this particular research. The activity theorists argue that CHAT is a coherent theoretical framework which establishes science education as participation in the community (Roth \& Lee, 2004). Learning in general, and science teacher education more specifically, can be seen as sites for social participation where cultural enactment occurs (Espinet \& Ramos, 2009). This could reform science education from the inside in a natural and logical way, while lifelong learning activities take place in|for the community, which is inseparable from individuals (Plakitsi, 2009).

Cultural-Historical Activity Theory has its origins in classic German philosophy (from Kant to Hegel), in the writings of Marx and Engels, and in the Soviet Russian cultural-historical psychology of Vygotsky, Leont'ev, and Luria. Today activity theory is becoming truly international and multidisciplinary. This process entails the discovery of new and old related approaches, discussion partners, and allies, ranging from American pragmatism and Wittgenstein to ethnomethodology and theories of self-organizing systems (Engestrom, 1999, p.20). Activity theory is a framework or descriptive tool (Nardi, 1996) that provides "a unified account of Vygotsky's proposals on the nature and development of human behaviour" (Lantolf, 2000, p. 8).

Two of CHAT's most important contributions concern the concept of mediation and the changes in human behavior. The first idea is that mediation with tools is not merely an idea. It is an idea that breaks down the Cartesian walls that isolate the individual mind from culture and society. The tools are both mental and physical. Examples of mental tools are the ability to measure, language (langue), and even some historical scientific experiments which changed our world. Examples of physical tools are magnifying glasses, simple balances, a textbook, operations on a PC, a social robot, or language (parole). Tools take part in the transformation of the object into an outcome, which can be desired or unexpected. They can enable or constrain activity. The second important idea is that humans can control their own behavior-not "from the inside," based on biological urges, but "from the outside," using and creating artifacts. 
Describing in brief the components of an activity represented in Figure 1, we mention subject, object, tools, rules, community, division of labor, and outcomes.

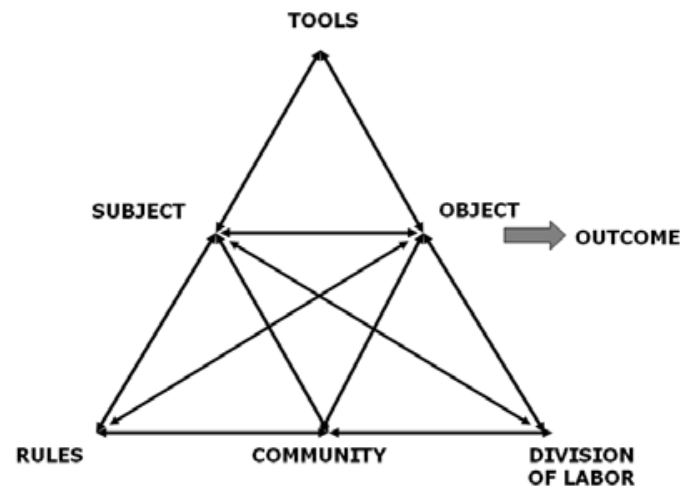

Figure 1: Visual Depiction of an Activity System (Engeström, 1987)

The subject of an activity system is the individual or group whose viewpoint is adopted.

An object 'refers to the 'raw material' or 'problem space' at which the activity is directed and which is molded or transformed into outcomes with the help of physical and symbolic, external and internal tools" (Engeström, 1993, p. 67, italics in the original). It precedes and motivates activity.

The interaction between the subject and the object is mediated by the tools, but it is simultaneously influenced by the rules, the community, and the division of labor.

The rules are explicit and implicit norms that regulate actions and interactions within the system (Engeström, 1993; Kuutti, 1996).

Community refers to participants in an activity system who share the same object.

The division of labor involves the division of tasks and roles among members of the community and the divisions of power and status.

Engeström's triangular model has become a common framework for representing the understandings based on this theory, as it provides a complete analysis for the structure of a given activity system, or the central activity. However, the third generation of activity theory needs to develop conceptual tools to understand dialogue, multiple perspectives, and networks of interacting activity systems (Engeström, 2001). According to Leontyev (Leontyev, 1981) there is a distinction between activities and actions. Activity (in human beings) is governed by its motive/motives and satisfies a need. Activity is carried out by a community. Actions are governed by their goals and often make sense only in a social context of a shared work activity. Action is carried out by an individual or group. Leontyev argues that:

"Let us now examine the fundamental structure of human activity in the conditions of a collective labour process [[...]] Processes, the object and motive of which do not coincide with one another, we shall call 'actions'. We can say, for example, that the beater's activity is the hunt, and the frightening of game his action" (Leontyev, 1981, p. 210).

For Engeström (1987) activity is a collective, systemic formation that has a complex mediational structure. An activity system produces actions and is realized by means of actions. However, activity is not reducible to actions. Actions are relatively short-lived and have a temporally clear-cut beginning and end. Activity systems evolve over lengthy periods of socio-historical time, often taking the form of institutions and organizations.

Also, the theorists argue that:

"The theory of activity proposes three levels of interaction between an organism and its environment. At the level of concrete operations, the critical factor in interactions is the external conditions involved in performing operations. This level is prominent in the psyches of animals and unconscious operations in humans. The second level is the level of higher primates and humans. At this level the critical factors are the goals of actions and the means of performing the actions. The third level of interaction is the level of the individual personality and the complex social environment. The crucial components here are activity and the individual's motives for engaging in activity" (Zlotnikov, 1997, p. 42).

Apart from the basic triangle of CHAT, many prominent socioculturalists have supported some major trends of the theory. We focus on the concept of participation (Roth \& Lee, 2004). Science education as participation in the 
community can work as a syllabus for teachers/researchers in science education in order to rethink the scope of scientific literacy. The core tendency is to construct theoretical assertions from an example or a case study. Some may consider this approach to be methodologically problematic, but we oppose this view, because each specific situation can contribute to a bottom-up approach to rethinking science education in a sociocultural context. We also oppose the formation of the theoretical assertions following a top- down approach, for example, from general pedagogical principles to everyday practices. We believe that it cannot help practitioners apply CHAT in their everyday settings because of the gap between general principles and practice.

In this paper, we outline an analysis methodology based on the theoretical framework briefly described that can be used to guide designing and analysing activities conducted in science education.

\section{Rationale}

The rationale articulates the general problem, the specific problem of teaching plant processes, the innovative teaching proposal following a didactical transformation, the multiple levels of expected outcomes and the aim of the study.

\subsection{General Problem}

Our research has been influenced by the continuing and growing interest of global educational community in the teaching of natural sciences at all levels of education (AAAS, 1989; OECD, 2007; Osborne \& Dillon, 2008). In recent years, many countries have reformed their science curriculum and major agencies stress the need for scientific literacy and develop programs for both evaluating the results of the teaching of science (Programme for International Student Assessment [PISA]) and for the promotion of science (Project 2061).

Dillon (2009) emphasized the value of scientific literacy in his analysis about scientific literacy and curriculum reform as it was reported by the High Level Group on Science Education:

"There is obviously a need to prepare young people for a future that will require good scientific knowledge and an understanding of technology. Science literacy is important for understanding environmental, medical, economic and other issues that confront modern societies, which rely heavily on technological and scientific advances of increasing complexity" (Dillon, 2009, p. 205).

Dillon's analysis reported also the characteristics of certain European attempts to reform the science curriculum, such as Britain, the Netherlands and Turkey and also some interesting parallels with what has been happening the last period in North America, Australasia and Africa regarding science curricula.

Undoubtedly, nowadays science education is a high priority of education worldwide and also a challenge for science educators and policy makers. For this purpose the Greek Ministry of Education changed the curriculum in 2003 towards Cross Curricular/Thematic Framework (CCTF) and the Individual Subject Curricula for compulsory education, which introduced a cross-thematic approach to learning. Currently, this article's co-author is co-ordinating an ongoing reform towards a new curriculum for the new school of the $21^{\text {st }}$ century. This new curriculum is now in its pilot implementation and testing. Our research dovetails the two curricula enhancing inquiry based learning and the cultural dimension of science education (Pedagogical Institute, 2003; 2011).

In both curricula, the teaching of natural sciences in compulsory education in Greece and especially in primary schools is integrated (including physics, chemistry, biology, geology, and geography) into the subject called Studies of the Environment, taught in the first four grades, and in the subject called Explore the Natural World, taught in the last two grades. One exception is geography, which is taught as an independent subject in the last two grades of primary school.

According to the new pilot curriculum for Natural Sciences, the aim of teaching science in compulsory education is incorporated in the general aims of education, which are the well-rounded and balanced development of the individual through the development of critical thinking abilities and a positive attitude towards creative action on a personal and a social level. In our approach we try to move the discussion more from the society to the individual and less from the individual to the society.

The new pilot curriculum includes a major thematic unit called The life around us where the module of living things is dominant in all grades of primary school.

\subsection{The Specific Problem of Teaching Plant Processes}

The module of living things is a main subject of biology which is a subfield of natural sciences and concerns the study of life in living organisms such as plants, animals, fungi, protista, bacteria, and all other forms of life. Most science 
curricula include it even from the very early years of schooling as foundational knowledge. However, research has shown that even in late elementary school there is a significant proportion of students who do not have an understanding of the concept of living things that corresponds with biological theory (Venville, 2004). The fact that biology course includes lots of abstract concepts may cause students to have difficulty in constructing knowledge (Keles \& Kefeli, 2010). According to our opinion, we may have failed because we teach living things in unauthentic learning environments and often without any enactment of learning communities. Our teaching proposal, as it will be presented in the following section, brings some more aspects of this topic to the fore. By this way, we hope to help, even a little, towards bridging the gap between theory and praxis.

Moreover, this researching study faces the problem of inadequate teaching of plant processes. Plant processes are a difficult biological topic for the students, partially because they are characterized by a number of conceptions that usually make the teaching of these concepts inadequate (Lumpe \& Staver, 1995; Canal, 1999; Carlsson, 2002; Marmaroti \& Galanopoulou, 2006; Yenilmez \& Tekkaya, 2006; Keles \& Kefeli, 2010).

In parallel with the study of conceptions about the plant processes, a systematic and integrated approach in teaching requires an in-depth study of the historical dimension of these concepts. The history of Living Things concepts has mentioned by Aristotle (c. 384-322 BC) and his commonly held idea that plants get their 'food' from the soil (Carlsson, 2002). 'Living Things' was characterized for many centuries by the 'analogist' tradition between plants and animals, in which animal functions are the 'analog' and plant functions are the 'target', and that these analogies may impinge on the learning about plants (Barker, 2002). During the seventeenth century rises the 'experimentalism' model which underlies the scientific revolution. Furthermore, several authors have analyzed the history of the concepts of plant processes and argue that the presentation of historical vignettes in biology lessons is suitable for the curriculum at any level, such as the vignettes of Pristley who discovered the process of photosynthesis in the eighteenth century (Matthews, 2009).

The concepts of respiration and photosynthesis are important in the wider context of ecological understanding. For example, Lumpe and Staver (1995) report that for students to begin to understand life and life processes, they must understand the concepts associated with plant nutrition. Biologists and biology educators state that understanding energy issues in organisms, namely respiration and photosynthesis, is key to understanding more global issues, such as energy flow, food supplies, and other ecological principles. Nevertheless, during her research related to ecological understanding Carlsson states (2002), in summary, that photosynthesis is understood in many different ways and that the process of respiration in general, and in plants in particular, is unknown to a majority of students.

In depth, and according to a study by Yenilmez and Tekkaya (2006), students' conceptualizations of photosynthesis and respiration in plants are firstly that respiration is the exchange of carbon dioxide and oxygen gases through plant stomata and takes place in the cells of the leaves only and secondly that green plants take in carbon dioxide and give off oxygen when they respire or green plants respire only at night, when there is no light energy. Students often conceptualize that green plants do not respire, but they only photosynthesize. Other common conceptualizations are: carbon dioxide is used in respiration, which only occurs in green plants when there is no light energy to photosynthesize, photosynthesis provides energy for plant growth and plants respire when they cannot obtain enough energy from photosynthesis, and animals respire continuously because they cannot photosynthesize.

Canal (1999) argues that the common conceptions in primary school students regarding green plant nutrition are that plant nutrition is the process through which plants feed themselves and that plants are nourished by the substances that they take from the earth through their roots: water and mineral substances. Additional primary school students conceptualize that the substances that plants absorb from the earth form raw sap, which moves through the stalk and which allows the plant to grow and carry out its other vital functions. Sunlight is indispensable for the health of green plants, their strength, and good color. Without light, they become weak and may end up dying. Finally, plants breathe like animals, taking in and expelling air. If they do not do so continuously, they asphyxiate and die, like people.

Obviously, several studies note that students have many problems with issues related to plant processes. However, these processes are a vital part of plant life, and also responsible for the existence and success of all of the green plant life on Earth. Concerning the process of photosynthesis, Marmaroti and Galanopoulou (2006) report that photosynthesis is considered one of the main topics in school biology because of its importance for a basic understanding of how the world functions as an ecosystem and of how it acts as a bridge between the non-living and the living world. Due to this curricular and scientific significance, we choose the topic of plant processes, in order to teach these concepts in a different way, according to our proposal. Keles and Kefeli (2010) argue in their study that teaching concepts, such as photosynthesis and respiration, correctly and in a meaningful context is vitally important during primary and secondary terms in terms of a sufficient science education. That is, in order knowledge to be taught 
persistently and correctly, existing faulty conceptions should be replaced with right ones. Previous studies proved that, if they are not corrected, the misconceptions at primary school still persist at university level in the same way (Canal, 1999). To promote this meaningful teaching and learning, we suggest the following teaching proposal.

\subsection{The Innovative Teaching Proposal Following a Didactical Transformation}

This study attempts to develop an innovative teaching proposal and investigates the conceptualizations that children make about the processes of plants (photosynthesis, respiration, transpiration). For this purpose we proposed an integrated unit of the concepts of plant processes and taught it to primary school students of 10 to 11 years old.

Our teaching proposal tries to integrate the concepts of photosynthesis - respiration - transpiration in a common context and in this way overcoming the students' difficulties in learning these concepts. These concepts are dynamic interactive and interdependent processes, and not separate processes, which means that each process interacts with each other and depends on the others.

More specifically, plants, as living organisms, respire and by this process take in oxygen and remove carbon dioxide. Photosynthesis is the process of converting light energy to chemical energy and storing it in bonds of sugar. Respiration is the process where cells use this food (sugar) to release stored energy. So, respiration and photosynthesis are closely related and opposite processes. The complex substances (sugar) which are formed during photosynthesis are broken down into simpler ones in a process which uses oxygen (respiration). On the other hand, water in the roots is pulled through the plant by transpiration (loss of water vapor through the stomata of the leaves). Transpiration uses about $90 \%$ of the water that enters the plant. The other $10 \%$ is an ingredient in photosynthesis and cell growth. Without the process of transpiration, plants would not be able to complete their food production or photosynthesis.

This study sees the plant processes in the context of living systems and supports the connection of elementary science to everyday life. Despite the many difficulties students have in understanding the concepts of plant processes, these processes play an important role in the understanding of many aspects of living systems. Furthermore, one of the aims of science education is to make students learn meaningfully and use their learning to satisfy their needs in daily life. In this sense, considering all above studies and researchers, we designed this study to achieve two broad goals: (1) examine students' conceptualization about living things and (2) develop school teachers' training programs in teaching science.

\subsection{The Multiple Levels of Expected Outcomes}

Our innovative teaching proposal traces new paths in elementary science education and meets the cultural - historical activity theory framework. It is well-known that every science has its own epistemology, methods, methodology and consequently its own specificities. In this sense, science education is a field with its own specificities that are not found in other fields. Typically science education, including the teaching of plant processes, takes place in a school and is structured by a curriculum (formal science education). At the same time, science education could include out-of-school sites, such as science centres, museums, media, community-based programs, and new digital learning environments (informal science education). These environments serve very often the aims of teaching the concepts of plant processes with great success. In any case, science education comprises science content, teaching pedagogy and social science.

We tried to embed science in the socio-cultural context where it is being created. Especially, we posed some expected outcomes oriented by the science content but also the pedagogical and social practices. According to these expected outcomes and regarding the teaching of plant processes, students of 10 to 11 years old should:

-Be able to identify the parts of a plant.

-Explain in simple terms the plant processes.

-Develop positive attitudes and values about life and living things.

-Develop skills in arranging experiments through active participation.

-Develop communication skills, such as non- discursive communication (body language, facial expressions etc.).

This way any kind of individual participation in learning about living things is been articulated into the institutional (schooling) participation ending to the societal level of participation and vice versa. For example, the societal context forms the institutional focus and practice ending to the development of the individual participation as described above.

\subsection{Aim of the Study}

The problem of inadequate teaching of plant processes, as has been mentioned above, in parallel with our interest in Cultural-Historical Activity Theory, gave us the impetus to do this research. Also, given that there is much research on 
science education, only a few studies use CHAT. CHAT gives this appropriate context to study the interactions taking place during the teaching and to analyse some aspects of science education.

This study is designed to investigate how primary school students conceptualize plant processes, while students are involved in different actions. We are interested in examining whether the implementation of a particular teaching proposal which focuses on a didactical transformation is successful. Our research focuses on the following questions:

(1) In which way the different actions of teaching the concepts of photosynthesis, respiration and transpiration interact each other into our integrated teaching proposal?

(2) How do students respond to these educational actions?

(3) Did students achieve the goals of our educational actions?

\section{Methods}

The current research used a case study design and a series of qualitative data collection methods to investigate the process of learning when 10-year-old students (5th grade) learn about plants. We studied the way they conceptualize integrated concepts of plant processes (photosynthesis-respiration-transpiration). The research methodology followed a qualitative design, involving classroom observations and data analysis. We collected data by video recordings and analysed how biology education is progressing at schools under the CHAT framework. Tobin (2006) argues that research in classrooms focuses on better understanding of teaching and learning and using what is learned to create and sustain improved learning environments.

The sample used in this study consisted of 16 students in primary school (5th grade) from the island of Corfu. All of them were in mixed-ability groups and had not received any instruction about plant processes in previous lessons on natural sciences.

Eftychia, acting as teacher/researcher, has 4 years of teaching experience in the early years of schooling. She participated in the study anticipating that the expected feedback about children's conceptualizations of plant processes can be used to plan future teaching approaches. She designed a sequence of tasks in order to help students to acquire learning about plant processes. The research consisted of 3 days of out-of-school in-service training of the teacher/researcher, 4 days in class preparation of the experiments, and 1 day in-class teaching and inference procedure. The 16 students were from mixed cultural and socioeconomic backgrounds, including children whose parents originated from Greece, Albania, and the Czech Republic. The teacher/researcher informed parents and guardians of all children in the class about the research and informed them of their right to withdraw their child from participation in the research at any time. No parent or guardian chose to withdraw a child from this research. Students also were informed in simple terms about the reasons for the researcher's presence in the classroom and were given the choice of whether they wanted to participate or not. No student decided to withdraw from the research.

According to the old Greek National Curriculum, natural sciences lessons in 5th and 6th grades of primary school should take place three times a week (3 different teaching hours). At this time the school science textbooks keep an old and traditional module of plants consisting of four separate lessons, which are taught during four different teaching hours. The four lessons are (a) The Parts of Plants, (b) Photosynthesis, (c) Respiration, and (d) Transpiration. Our teaching approach was partly based on the above lessons (as we kept the same experiments), but took place in a different articulation. Our approach for the unit Plants was holistic, since our basic teaching objective is students coming to understand plants as living things with dynamic interactive and interdependent processes. So the innovative implementation took place without using the current school science textbooks, but using our own worksheets, which we had been prepared for the purposes of research (see Appendices I, II). Our teaching proposal consisted of two different parts: one part of preparation and one part of class teaching. Both parts were done with the cooperation of the teacher/researcher and students. Also, the teacher/researcher designed the instruction according to the interests of students. For four days (Monday-Thursday) students and teacher/researcher collected the materials for the experiments and prepared the experiments, since most of them needed more than one day to be prepared (see Figs. 2 and 3). For example, they had to cover some leaves of a plant with foil for three days, before studying what happens to leaves without light (photosynthesis). 

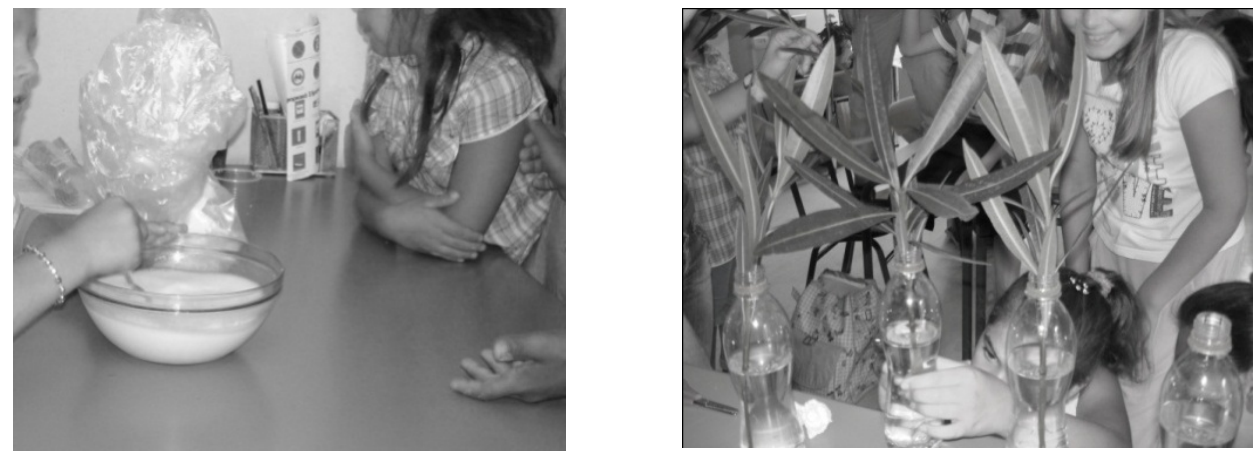

Figures 2 \& 3: Students are Preparing the Experiments for Respiration and Transpiration 3 Days Before the Lesson (photo from author's archive)

Since we wanted to approach the unit Plants within the same day and not to teach the three plant processes separately on different days, the discussion and the inference procedure about plant processes occurred on Friday, when all experiments were ready. That day was named by students The Flower Day, since they were very excited about the expected teaching. In order to create an environment in which cooperative learning can take place, students were divided into groups of four. The research methodology followed a qualitative design, involving classroom observations and data analysis.

During the Flower Day, the teacher/researcher designed a series of learning tasks so that students could approach inquiry based learning about plant processes. At first, teaching plant processes started with a review of plant parts and what plants need to grow. All students had some prior knowledge of both of these concepts. Each student was asked to say his/her opinion about the plants' needs for growth. Most students answered "sunshine, water, and soil." The teacher/researcher introduced students to the new concepts by presenting them with a computer-aided presentation about the three main plant processes. The presentation contained mainly shapes and images, since the new terms were very difficult for most children to understand. According to the Mauseth (2009), the definitions of these three concepts of biology education are:

"Photosynthesis is the combination of carbon dioxide with water to form carbohydrates in the presence of light" (Mauseth, 2009, p.286).

"Respiration is the process that breaks down complex carbon compounds into simpler molecules and simultaneously generates the ATP used to power other metabolic processes" (Mauseth, 2009, p.315).

"Transpiration causes leaf cells to lose water" (Mauseth, 2009, p.346).

After the teacher/researcher's presentation and the initial discussion with the students, the teaching moved on to the next actions: the experimental testing and implementation of the new learning concepts. These actions took place through a series of teaching strategies, mainly through collaborative work between students and teacher during the experiments. For this reason, the teacher/researcher gave the students a worksheet (one for each group), in which they had to work and do the experiments (see Appendix I). The sequence of experiments, which were included in pedagogical actions with specific goals, was as follows:

1. Finding out that humans exhale carbon dioxide when they breathe out.

2. Discovering that plants also exhale carbon dioxide.

3. Finding out that certain foods contain starch.

4. Discovering that leaves also contain starch.

5. Discovering that leaves turn yellow if there is no light.

6. Discovering that yellowed leaves contain no starch.

7. Discovering that plants lose water into the atmosphere.

8. Discovering that plants lose water through their leaves.

9. Discovering that plants lose water mainly through the lower surfaces of their leaves.

All experiments involved observations, collecting data by students, who worked in groups as they conducted the experiments. During the experiments, very often students asked their teacher to go back to the presentation to discuss 
some concepts or to check their results of the experiments. This procedure gave students a positive feedback and supported their learning about plant processes. This was mainly achieved through discussion among teacher and students and among groups. Simultaneously, the teacher/researcher gave the groups another two worksheets, on which the students had to check their understanding about the new concepts (see Appendix II). In this way the teacher/researcher evaluated what students had learned and if the teaching was effective. Both worksheets were of varying levels of difficulty for students and necessitated the cooperation of group members and the development of critical thinking. Open-ended questions and problems from everyday life were selected, instead of multiple-choice or closed-ended questions. Students had to compose their thoughts and what they have learned in order to answer the questions. For example, in worksheet B students had the opportunity to describe the main processes of a plant in their own way (by using shapes, images, words, etc.). All groups had a good understanding of plant processes and responded positively to their evaluation.

\section{Results}

The study was designed to investigate how primary school students conceptualize plant processes, while students are involved with different actions. The data obtained by classroom observations and video recordings were interpreted with qualitative data analysis method. The data were classified as students' arguments before the implementation and students' arguments after the implementation. In cultural-historical activity theory, agency, knowing, and learning are not properties of individuals but are understood in terms of situated and distributed "engagement in changing processes of human activity" (Roth \& Lee, 2004). In this sense, students' arguments indicate the changing process of teaching activity, where all the components of the activity interact with each other. The students' arguments do not include static students' views on the teaching topic but indicate the changing process during the teaching, as it was restructured when different tools mediated the activity. Considering the limited length of a paper, below we present the data of our analysis arising after coding.

\subsection{Students' Arguments before the Implementation}

As students' arguments before the implementation, we mention the oral statements about plants and their processes, which were said by students during the initial discussion between teacher and students and also between students. The teaching started with a review of plant parts and what plants need to grow and then with a discussion about plant processes. The teacher/researcher presented students a computer-aided presentation about the main plant processes (photosynthesis, respiration, transpiration) with many shapes and images. She explained analytically the processes and asked students to express their opinion. All students responded and gave some interesting arguments, but most of them were very cautious to the new concepts and had many difficulties in making their justifications. Generally, students' arguments were characterized by a poor vocabulary about these concepts. The most common and interesting examples are presented in Table 1.

Table 1: Students' Arguments before the Implementation

\begin{tabular}{ll}
\hline Concept & Arguments \\
\hline Living things/Non-living things & - All plants are living things \\
& - Plants are living things but not as animals and humans are \\
Parts of a plant & - Plants have roots, stems and leaves \\
& - Every plant is different \\
& - Plants have roots to stand up \\
Needs of a plant & - Plants need water and sunlight to grow up \\
& - Plants need care to grow up \\
Food production & - The food of plant is water \\
& - Plants do not need any food \\
Respiration & - Plants do not do respiration \\
& - Plants take in carbon dioxide and give off oxygen when they respire \\
Gas exchange & - Plants respire as humans do \\
Plant processes & - There is no gas exchange between plants and environment \\
\hline
\end{tabular}


- Plants keep the water in their roots.

Photosynthesis

- Plants make their food during photosynthesis

- The food of a plant is water and sunlight

Transpiration

- Plants do not need as much water as they take in

\subsection{Students' Arguments after the Implementation}

As students' arguments after the implementation, we mention the oral statements of students during the final discussion (recapitulation), as well as their written word as stated in the worksheets. In this stage all the students participated actively and gave the following answers, as stated in Table 2.

Table 2: Students' Arguments after the Implementation

\begin{tabular}{ll}
\hline Concept & Arguments \\
\hline Needs of a plant & - Plants need food and air to grow up, like humans \\
& - Plants need air, soil, water, light and space to grow \\
& - Plants need more respect \\
& - The presence of light is necessary during photosynthesis \\
& - Plants make their own food \\
Photosynthesis & - Plants need only light, carbon dioxide and water to make sugar \\
& - Photosynthesis is responsible for the existence and success of all of the \\
& green plant life on Earth \\
& - Plants respire as humans do \\
& - Plants obtain oxygen and remove carbon dioxide during respiration \\
Respiration & - Plants lose water mainly through their leaf surfaces, and especially \\
Transpiration & through some openings called stomata \\
& - Plants lose water into the atmosphere \\
Plant processes & - Photosynthesis and respiration are opposite processes \\
& - Plants do some very important processes that are admirable \\
& - Photosynthesis is a vital part of plant life \\
& - Plants need energy to live, to grow, and to make more of themselves \\
\hline
\end{tabular}

Comparing the students' arguments before and after the implementation, it can be seen that the students' answers were characterized by some important changes. Before the implementation, students made their claims, without any definitive justification to the concept. Their arguments were based on prior knowledge (some of it was incomplete or incorrect or both) and had not any justification or explanation about the concepts. After the implementation, students enriched their vocabulary and expressed the new concepts in a very different way. The argumentation process changed over time and students provided data, based on their experimentally findings. These data supported students' arguments and made students more confident to expose their opinion. So, students explained in simple terms the basic processes of a plant and were able to understand plants as living things with interactive processes.

Regarding the participation of the students during the teaching, we can mention the following. During the teaching, students discussed, shared and compared their ideas and understandings into their groups and had a successful collaboration. The whole collaborative class level was high, as the procedure of the experiments was a challenge for the students. The students worked together to achieve the goals of their group and created a great learning environment. Some students, who did not speak very often in class, felt during the teaching more comfortable speaking in front of their groups. In the final discussion with the teacher/researcher all the students exposed their ideas and arguments about the concepts of plant processes and expressed their satisfaction about the teaching. Many students said: "It was a real Flower Day!". In addition, when the teacher asked the students to express their opinion about plants, as a final proposition of the teaching, most of the students said that by that day they would address plants in a different way. Students recognized the usefulness of the plants and also that humans have to respect plants, as living things with complex needs and processes. 


\subsection{Analyzing Actions}

The research rationality led us to apply CHAT framework as an appropriate framework to analyse the actions which took place during our teaching. The use of the CHAT framework enables participants to provide a detailed description of the connections within the lesson, as teacher/researcher and students work together to achieve individual and common goals. The implementation of the CHAT context through teaching in a school classroom supports the concept that the community is continually changing, shaped by the interactions of the subjects.

In this study, the central activity is the educational system, which includes other interacting activity systems and consists of actions. The central activity of the educational system consists of subjects (students, teachers, educational policy makers, parents), who act on certain objects, which are necessary in order to achieve the desired outcomes of education. The objects include knowledge, skills, values and attitudes students should exhibit that reflect the outcomes. The outcomes of education include the development of individual morally, intellectually, physically, socially and aesthetically. These outcomes are needed by both individual and society. This activity is mediated by tools, such as language, thought, schools, and curricula. The activity is also mediated by the community in which the activity is being carried out. The community provides the rules that regulate the activity and constrains actions and interactions within the activity system. Such rules may be the practices of the educational system and the collaboration between the subjects. Finally, the division of labor refers to the division of tasks between the members of the community, such as the responsibility that subjects share with the community in the activity system.

At the same time, the activity of the educational system interacts with other activity systems and consists of actions. One central interacting activity system is the activity system of teacher training. The improvement of in-service teachers' training is our main goal of our study, under which we investigated innovative processes and practices in the teaching of living things.

In this context, our innovative teaching of plant processes constitutes an action of the central activity system of the educational system and contains interacting actions that share a common goal. In figure 4, we represented the interacting actions of the teaching of plant processes and the way they share the common goal. The interacting actions contain the action of teaching the concept of respiration, the action of teaching the concept of photosynthesis and the action of teaching the concept of transpiration. The teaching of plant processes aimed to the understanding of plants as whole entities. The main goal of the teaching was students' learning about plants and their processes and the achievement of the outcomes (attitudes and values about life and living things, scientific literacy, motivation to learn science, communication skills). First of all, students learn the parts of a plant and their usefulness. They learn that plants are living organisms and therefore respire and then that plants are photosynthetic, which means that they manufacture their own food molecules using energy obtained from light. Also, students had to learn that plants lose water through the process of transpiration. All these concepts were the basis of understanding plants as living things with dynamic interactive and interdependent processes, and not separate processes. Our innovative approach to teaching, as mentioned in previous pages, followed a specific transformation which fostered the understanding of concepts in an interdependent context.

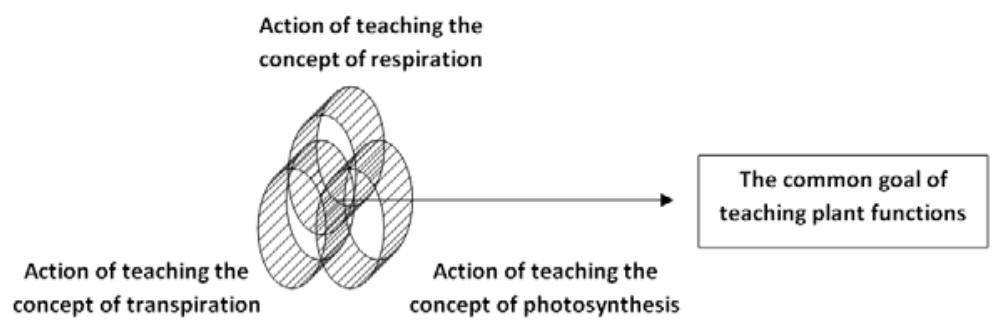

Figure 4: Interacting Actions in the Teaching of Plant Processes

\subsection{A Model of Achievement the Goal of Plant Respirations}

In this model, there are two interacting actions that are relevant to the teaching of the concept of plant respiration. The action of teaching that humans expel carbon dioxide when breathing out and the action of teaching that plants exhale carbon dioxide are foregrounded as constituting the understanding that plants breathe. These actions are inherently interrelated, in order to facilitate the understanding that plants breathe and absorb free molecules of oxygen $\left(\mathrm{O}_{2}\right)$ and use them to create water, carbon dioxide, and energy, which help the plants grow. In both actions, the subjects are the 
elementary students and the teacher, who interact with the community (school classroom), the rules as a basis for mediation of interactions (how a student collaborates with another student, a student with the teacher, a group with another group, a group with the teacher), and the division of labor (group work). The tools used for the action of teaching that humans expire carbon dioxide when breathing out were language, the body, thought, a worksheet, a glass, water, and a drinking straw. The tools used for the action of teaching that plants exhale carbon dioxide were language, the body, thought, a worksheet, two bottles, water, and celery. Both actions share a common goal, the understanding that plants breathe. The achievement of the common goal was made by the following process: Goal 1 of the first action was the human breath and carbon dioxide. Goal 1 is being transformed from an initial state of an experiment finding into a collectively meaningful goal 2 constructed by the pedagogical action (the understanding of presence of carbon dioxide in human breath). Goal 1 of the second action was the plants and carbon dioxide. Also, this goal 1 is being transformed into a collectively meaningful goal 2 constructed by the pedagogical action (the understanding of the presence of carbon dioxide around living plants). Both goals are being transformed into potentially shared or jointly constructed goal 3 , which is the understanding that plants breathe.

\subsection{A Model of Achievement the Goal of Photosynthesis}

In this model, there are four interacting actions that are relevant to the teaching of the concept of photosynthesis. The action of teaching that certain foods contain starch, the action of teaching that leaves contain starch, the action of teaching that leaves turn yellow if there is no light, and the action of teaching that yellowed leaves contain no starch are foregrounded as constituting the understanding that plants make their own food. These actions are inherently interrelated, in order to facilitate the understanding that plants make their own food, through photosynthesis, the process a plant uses to combine sunlight, water, and carbon dioxide to produce oxygen and sugar (energy). In all actions, the subjects are the elementary students and the teacher, who interact with the community (school classroom), the rules as a basis for mediation of interactions (how a student collaborates with another student, a student with the teacher, a group with another group, a group with the teacher), and the division of labor (group work). The tools used for the action of teaching that certain foods contain starch were language, thought, a worksheet, bread, potatoes, and iodine. The tools used for the action of teaching that leaves contain starch were language, thought, a worksheet, plant leaves, and iodine. The tools used for the action of teaching that leaves turn yellow if there is no light were language, thought, a worksheet, plants, and aluminum foil. The tools used for the action of teaching that yellowed leaves contain no starch were language, thought, a worksheet, plant leaves, and iodine. All actions share a common goal, the understanding that plants make their own food. The achievement of the common goal was made by the following process: Goal 1 of the first action was the concept foods and starch. Goal 1 is being transformed from an initial state of an experiment finding into a collectively meaningful goal 2 constructed by the pedagogical action (the understanding of the presence of starch in certain foods). Goal 1 of the second action was the concept of plants and starch. Also, goal 1 is being transformed into a collectively meaningful goal 2 constructed by the pedagogical action (the understanding of presence of starch in plant leaves). Goal 1 of the third action was the concept of plants and sunlight, which is being transformed from an initial state of an experiment finding into a collectively meaningful goal 2 constructed by the pedagogical action (the knowledge that plants need sunlight). Goal 1 of the fourth action was the concept of absence of sunlight and sunlight. Also, this goal is being transformed into a collectively meaningful goal 2 constructed by the pedagogical action (the knowledge that yellowed leaves-because of the absence of sunlight-contain no starch). All the goals are being transformed into potentially shared or jointly constructed goal 3 , which is the understanding that plants make their own food.

\subsection{A Model of Achievement the Goal of Transpiration}

In this model, there are three interacting actions that are relevant to teaching the concept of transpiration. The action of teaching that plants lose water into the atmosphere, the action of teaching that plants lose water through their leaves, and the action of teaching that plants lose water mainly through the lower surface of their leaves are foregrounded as constituting the understanding that plants lose water into the atmosphere. These actions are inherently interrelated, in order to facilitate the understanding that plants lose water to the atmosphere through small openings on the underside of leaves called stomata. In all actions, the subjects are the elementary students and the teacher who interact with the community (school classroom), the rules as a basis for mediation of interactions (how a student collaborates with another student, a student with the teacher, a group with another group, a group with the teacher), and the division of labor (group work). The tools used for the action of teaching that plants lose water into the atmosphere were language, thought, a worksheet, a plant, a transparent bag, and water. The tools used for the action of teaching that plants lose water mainly through their leaves were language, thought, a worksheet, plant leaves, bottles, plant shoots, and water. The tools used for the action of teaching that plants lose water mainly through the lower surface of their leaves were language, thought, a worksheet, plant leaves, water, plant shoots, and vaseline. All actions share a common goal, the 
understanding that plants lose water into the atmosphere. The achievement of the common goal was made by the following process: Goal 1 of the first action was the concept plants and loss of water. Goal 1 is being transformed from an initial state of an experiment finding into a collectively meaningful goal 2 constructed by the pedagogical action (the knowledge that plants lose water into the atmosphere). Goal 1 of the second action was the concept of leaves and loss of water. Also, this goal 1 is being transformed into the collectively meaningful goal 2 constructed by the pedagogical action (the knowledge that plants lose water mainly through their leaves). Finally, goal 1 of the third action was the concept of loss of water and parts of leaves. Also, goal 1 is being transformed from an initial state of an experiment finding into a collectively meaningful goal 2 constructed by the pedagogical action (the knowledge that plants lose water mainly through the lower surface of their leaves). All the goals are being transformed into potentially shared or jointly constructed goal 3 , which is the understanding that plants lose water into the atmosphere.

\section{Discussion}

The current study investigated how primary school students conceptualize plant processes while students are involved with different actions. The qualitative data from this study make us very optimistic about the implementation of our teaching proposal. Students participated actively in all educational actions and achieved the goals of these actions. As mentioned in the previous section, after the teaching students were able to identify the parts of a plant and their usefulness and explain in simple terms the plant processes (photosynthesis, respiration, transpiration). The findings showed clear differences between students' arguments before and after the implementation. Also, students developed positive attitudes and values about living things (plants) and their communication skills. It is an encouraging finding that most of the students were positive about learning science through active participation and collaborative work in the future.

In addition, our CHAT analysis has been used to examine the actions of teaching the concepts of plant processes to primary students. This analysis showed that the interacting actions in the teaching shared the common goal of the teaching, which was the understanding of plant processes. However, the interacting activity systems and actions described in this study capture a moment in time of the learning process. The components of the CHAT triangle (community, subjects, etc.) are constantly changing as students evolve their thinking, explore new options, and interact with other activity systems. These issues should be further explored in order for CHAT to become better understood in educational research. Through this process, CHAT-based research and analysis should lead us to new forms of learning, knowing, and interacting among the three levels of participation - individual, institutional and societal. Students' achievements are being developed into the institutional level of participation (school, curriculum etc.) and ends to the society through the development of higher ordered conceptualization of plant functions (Figure 4). Also, students' attitudes about concerving the environmental resources for a sustainable way of plant functioning improves the societal level of participation and vice versa. It is the societal level that poses the need and the institution (school) carries out a project to meet the need and inproves individual participation in a dynamic network of interactions.

Nevertheless, the results make us very optimistic about the implementation of a CHAT analysis in biology education in elementary schools. The study described in this paper contributes to a limited but growing interest in CHAT-based education research. This research, even though limited, could give impetus to the discussion of cultural studies of science education and, especially, teacher training in applications of the CHAT framework in science education. The experimentation on new processes in natural science pedagogical actions in the wider systems of activities demonstrates the importance of CHAT for science education and encourages us to study this research field. We believe that this field could yield new and useful insights into formal and informal science education. Doubtless, using CHAT analysis in science education about living things seems promising. It might be a way to fulfill the main objectives of science education, which are the motivation of students to experience meaningful learning, the achievement of scientific literacy, and the adoption of social attitudes and values.

\section{References}

American Association for the Advancement of Science. (1989). Science for all Americans. New York: Oxford University Press.

Barker, M. (2002). Putting Thought in Accordance with Things: The Demise of Animal-Based Analogies for Plant Functions. Science \& Education, 11, 293-304. http://dx.doi.org/10.1023/A:1015202609530

Canal, P. (1999). Photosynthesis and 'inverse respiration' in plants: An inevitable misconception? International Journal of Science Education, 21(4), 363-371. http://dx.doi.org/10.1080/095006999290598 
Carlsson, Br. (2002). Ecological understanding 1: Ways of experiencing photosynthesis. International Journal of Science Education, 24(7), 681-699. http://dx.doi.org/10.1080/09500690110098868

Dillon, J. (2009). On scientific literacy and curriculum reform. International Journal of Environmental \& Science Education, 4(3), 201-213.

Engeström, Y. (1987). Learning by Expanding. An Activity-Theoretical Approach to Developmental Research. Helsinki: Orienta-Konsultit.

Engeström, Y. (1993). Developmental studies of work as a testbench of activity theory: The case of primary care medical practice. In S. Chaiklin \& J. Lave (Eds.), Understanding practice: Perspectives on activity and context (pp. 64-103). Cambridge, MA: Cambridge University Press. http://dx.doi.org/10.1017/CBO9780511625510.004

Engeström, Y., Miettinen, R., \& Punamaki R. (Eds.) (1999). Perspectives on activity theory. New York: Cambridge University Press. http://dx.doi.org/10.1017/CBO9780511812774

Engeström, Y. (2001). Expansive learning at work: Toward an activity theoretical reconceptualization. Journal of Education and Work, 14(1), 133-156.

Espinet, M., \& Ramos, L. (2009, August 31-September 4). Multilingual science education contexts: Opportunities for pre-service science teacher learning. Paper presented at the symposium Cultural Studies of Science Education in Europe: Mapping Issues and Trends at the European Science Education Research Association (ESERA) biannual conference, Istanbul, Turkey.

European Commission. (2004). Europe needs more scientists. Report by the High Level Group on Increasing Human Resources for Science and Technology in Europe. Brussels: European Commission.

Keles, E., \& Kefeli, P. (2010). Determination of student misconceptions in "photosynthesis and respiration" unit and correcting them with the help of cai material. Procedia Social and Behavioral Sciences, 2, 3111-3118. http://dx.doi.org/10.1016/j.sbspro.2010.03.474

Kuutti, K. (1996). Activity theory as a potential framework for human-computer interaction research. In B. A. Nardi (Ed.), Context and consciousness: Activity theory and human-computer interaction (pp. 17-44). Cambridge, MA : The MIT Press.

Lantolf, J. P. (2000). Introducing sociocultural theory. In J. P. Lantolf (Ed.), Sociocultural theory and second language learning (pp. 1-26). Oxford: Oxford University Press.

Leontyev, A.N. (1981). Problems of the Development of the Mind. Moscow: Progress Publishers.

Lumpe, A., \& Staver, J. (1995). Peer collaboration and concept development: Learning about photosynthesis. Journal of Research in Science Teaching, 32(1), 71-98. http://dx.doi.org/10.1002/tea.3660320108

Marmaroti, P., \& Galanopoulou, D. (2006). Pupils' understanding of photosynthesis: A questionnaire for the simultaneous assessment of all aspects. International Journal of Science Education, 28(4), 383-403. http://dx.doi.org/10.1080/09500690500277805

Matthews, M. (2009). Science and Worldviews in the Classroom: Joseph Priestley and Photosynthesis. Science \& Education, 18, 929-960. http://dx.doi.org/10.1007/s11191-009-9184-8

Mauseth, J. (2009). Botany. An introduction to plant biology. Canada: Jones and Bartlett Publishers.

Nardi, B. A. (1996). Activity theory and human-computer interaction. In B. A. Nardi (Ed.), Context and consciousness: Activity theory and human-computer interaction (pp. 69-103). Cambridge, MA: MIT Press.

Next Generation Science Standards. (2013). Retrieved August 3, 2013, from http://www.nextgenscience.org/

Organisation for Economic Co-operation and Development. (2007). PISA 2006: Science competencies for tomorrow's world. Volume 1: Analysis.Paris: OECD. Retrieved August 4, 2011, from http://www.keepeek.com/Digital-Asset-Management/oecd/education/pisa-2006_9789264040014-en

Osborne, J., Dillon, J., \& King's College London. (2008). Science education in Europe: Critical reflections. London: The Nuffield Foundation.

Pedagogical Institute. (2003). Cross-thematic curriculum framework for natural sciences. Translated from the official Gazette issue B, nr 303/13-03-03 and issue B, nr 304/13-03-03. Athens: Pedagogical Institute. Retrieved August 4, 2011, from http://www.pi-schools.gr/download/programs/depps/english/19th.pdf 
Pedagogical Institute. (2011). Curriculum for natural science. Retrieved October 8, 2011, from http://digitalschool.minedu.gov.gr/info/newps.php

Plakitsi, K. (2009, August 31-September 4). Activity theory in formal and informal science education (ATFISE project). Paper presented at the symposium Cultural Studies of Science Education in Europe: Mapping Issues and Trends at the European Science Education Research Association (ESERA) biannual conference, Istanbul, Turkey.

Plakitsi, K. (2013). Activity Theory in Formal and Informal Science Education. The ATFISE project . In K. Plakitsi (Ed.), Activity Theory in Formal and Informal Science Education (pp. 1-15). Rotterdam: Sense Publishers.

Roth, W.-M. (2004). Activity Theory and education: An introduction. Mind, Culture, and Activity, 11(1), 1-8. http://dx.doi.org/10.1207/s15327884mca1101_1

Roth, W.-M., \& Lee, S. (2004). Science education as/for participation in the community. Science Education, 88(2), 263-291. http://dx.doi.org/10.1002/sce.10113

Tobin, K. (2006). Qualitative research in classrooms. In K. Tobin \& J. L. Kincheloe (Eds.), Doing educational research (pp. 15-57). The Netherlands: Sense Publishers.

Van Eijck, M., \& Roth, W. M. (2007). Rethinking the role of information technology-based research tools in students' development of scientific literacy. Journal of Science Education and Technology, 16(3), 225-238. http://dx.doi.org/10.1007/s10956-007-9045-7

Venville, G. (2004). Young children learning about living things: A case study of conceptual change from ontological and social perspectives. Journal of Research in Science Teaching, 41(5), 449-480. http://dx.doi.org/10.1002/tea.20011

Yenilmez, A., \& Tekkaya, C. (2006). Enhancing students' understanding of photosynthesis and respiration in plant through conceptual change approach. Journal of Science Education and Technology, 15(1), 81-87. http://dx.doi.org/10.1007/s10956-006-0358-8

Zlotnikov, I. (1997). Metatheoretical research in soviet psychology. In E. L. Grigorenko, P. Ruzgis \& R. J. Sternberg (Eds.). Psychology in Russia: Past, present, future (pp. 39-58). Commack, New York: Nova Science Publishers, Inc.

\section{Appendix I: Plant processes: Worksheet A (Group ...)}

When you blow into the glass containing limewater...

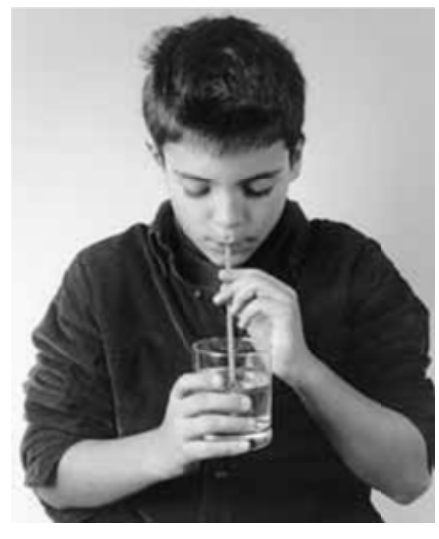

Words to use: Carbon dioxide, expire, inhale, oxygen, cloudy 


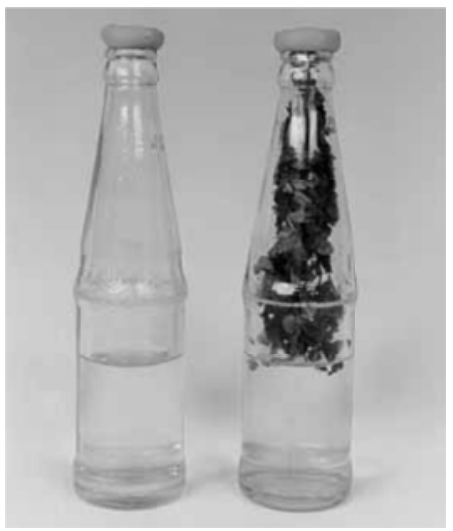

You fill two bottles with limewater (place one stalk of celery in the first bottle)...

Words to use: respiration, oxygen, carbon dioxide

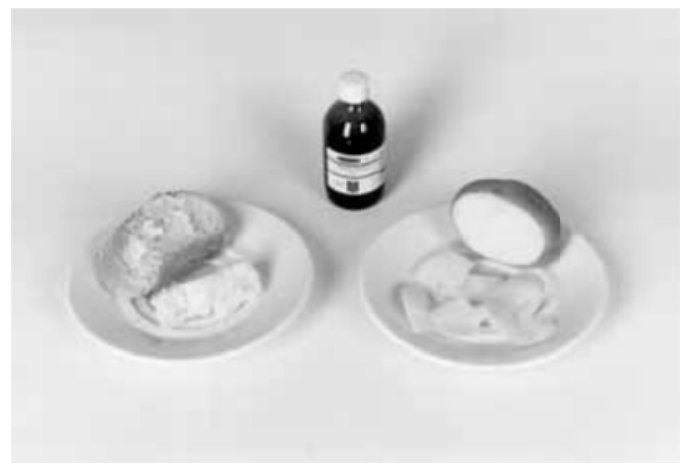

When you add iodine...

Words to use: starch, bread, potatoes, color

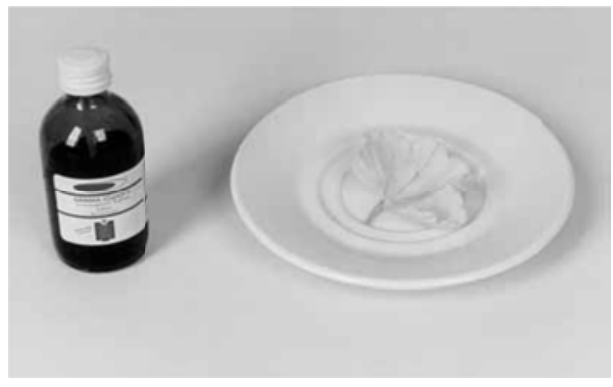

When you add iodine...

Words to use: discolored leaf, starch 


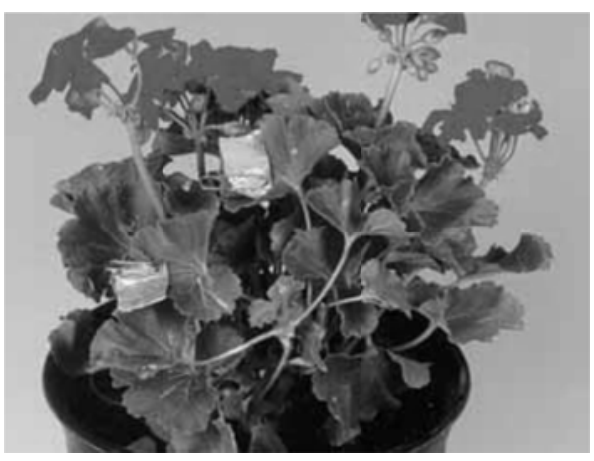

You covered some leaves with aluminum foil...

Words to use: observe, color, yellow, light

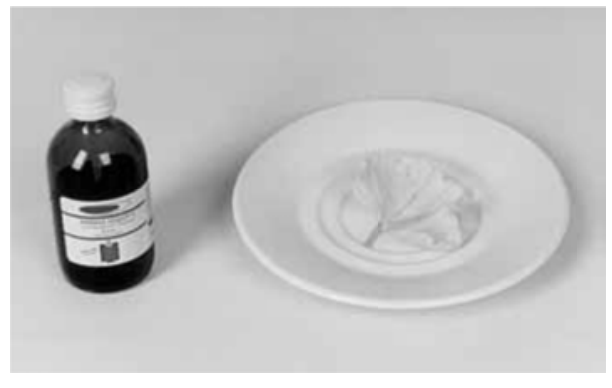

The leaves you had covered with foil...

Words to use: discolored leaf, iodine, light

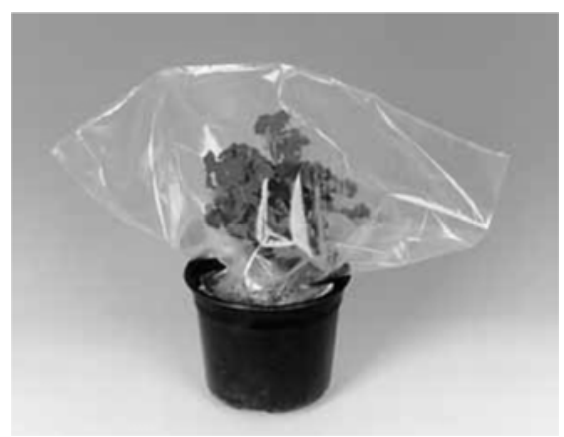

You covered a plant in a pot with a transparent bag...

Words to use: water, light, drops

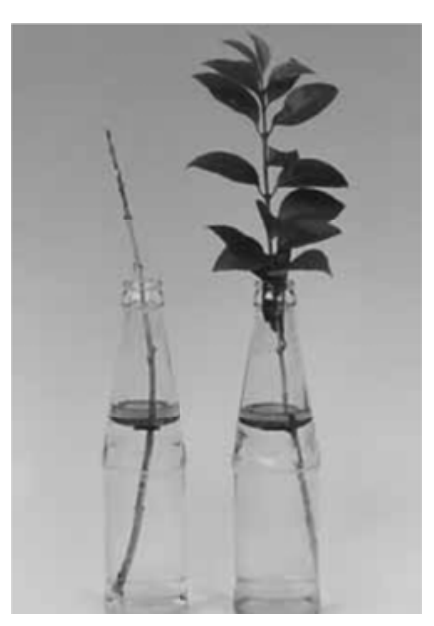

You filled two identical bottles with water...

Words to use: oil, light, stem, leaves, water level 


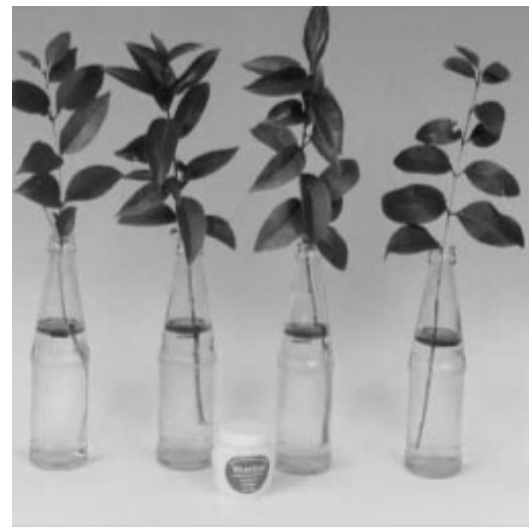

You put similar stems of a plant in four different bottles...

Words to use: light, oil, stems, leaves, Vaseline, upper surface, lower surface, water level

\section{Appendix II: Plant processes: Worksheet B (Group ...)}

A. Aphrodite is home again after the summer holidays. She opened the door of her room and went inside. Immediately she opened the shutters to get light into the room. She was very surprised when she saw that her favourite basil had wilted. - But how did it happen? My grandfather watered it every day, thought Aphrodite. Without wasting any time, she found her school textbook, which talked about plants. In one chapter, she found the plant experiments they had done in school. Unfortunately, the conclusions were missing. Can you help Aphrodite understand what had happened to her basil?

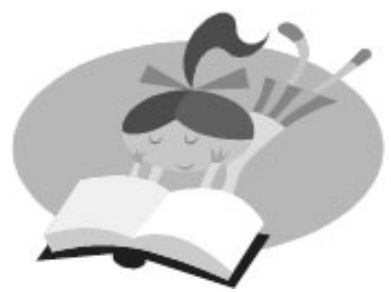

B. Mike went on vacation for a few days and left this note to his friend Eva. Do you agree with the advice? Is it enough?

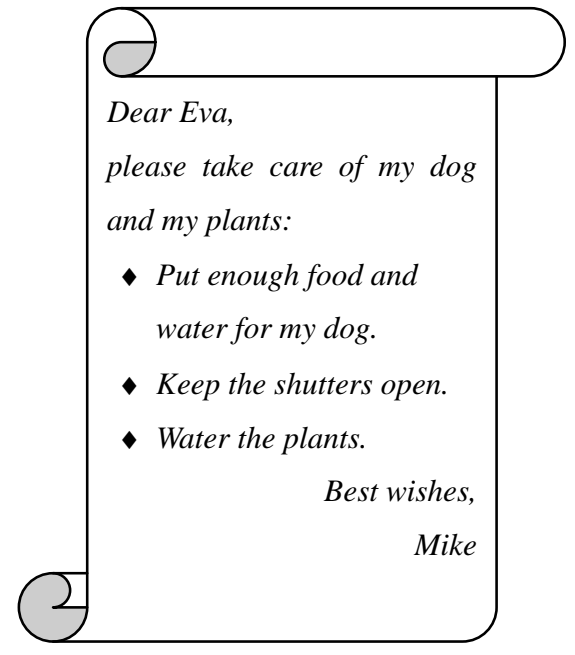


C. "Respiration and photosynthesis are opposite processes." Can you explain this statement? 